\title{
ACCOMPLISHMENTS AND CONTRIBUTIONS OF SIX SIGMA APPROACH FOR SUSTAINABILITY OF SERVICE AND MANUFACTURING INDUSTRY IN TERMS OF QUALITY IMPROVEMENT
}

\author{
DOI: 10.17261/Pressacademia.2021.1449 \\ RJBM-V.8-ISS.3-2021(2)-p.167-180
}

\section{Aysenur Erdil}

Istanbul Medeniyet University, Department of Business Administration, Istanbul, Turkey. runesyalidre@gmail.com , ORCID:0000-0002-6413-7482

\begin{tabular}{l} 
Date Received: June 7, $2021 \quad$ Date Accepted: September 9, 2021 \\
\hline To cite this document \\
Erdil, A., (2021). Accomplishments and contributions of six sigma approach for sustainability of service and manufacturing industry in terms of \\
quality improvement. Research Journal of Business and Management (RJBM), 8(3), 167-180. \\
Permanent link to this document: $\underline{\text { http://doi.org/10.17261/Pressacademia.2021.1449 }}$ \\
Copyright: Published by PressAcademia and limited licensed re-use rights only.
\end{tabular}

\section{ABSTRACT}

Purpose- This study investigates the development, advantages, customer satisfaction, and problems of six sigma principles, provides a brief introduction of the six-sigma organizational structure and its application in industry implementation, and highlights the major elements impacting successful six sigma deployments. In addition, the objective of this research is to evaluate the fundamental ideas of six sigmas, its advantages, and effective implementation methodologies.

Methodology- Quality Management-Process improvement is already a critical systematic process for gaining a competitive edge and improving performance. Whereas Six Sigma might have been initially established with manufacturing techniques, it is now employed through service organizations and service operations in practically every industry and by some service sectors (e.g., transportation, telecom, and healthcare) to increase profitability and performance. In addressing critical challenges, business managers implement Six Sigma in business marketing, financial, operations management, regulatory, and employee relations operations. Generally, the Six Sigma approach has been employed in the industrial sector of industry.

Findings- This research, in terms of direction, includes exemplary practices/applications from the service industry and manufacturing sector, as well as other industries (e.g., transportation and mobile communications-telecommunications) that are pioneers and entrepreneurs-innovators in applying the procedures via quality function deployment. We provide insights acquired from past successes. The work incorporates the principles acquired from outstanding six sigma enterprises, discusses the principles of managerial position and appropriate six sigma application deployment, and examines future enhancements to the six sigma method.

Conclusion- Six sigma concepts and practices that are beneficial could flourish through constantly improving the management structure. According to the findings of this study, the principles of effective application comprise higher management endorsement and engagement, strategic alignment, skills development, platforms, and connections to personnel management efforts- initiatives.

Keywords: Business, quality function, quality management, six sigmas, service and manufacturing industry. JEL Codes: M10, L15, O14

\section{INTRODUCTION}

Quality is more than a checkbox to be checked or a platitude to be said. Failures caused by inadequate leadership, inadequate assurance, and reluctance to change may and can have devastating implications for enterprises, communities, and community as a whole. Quality control is concerned with making organizations perform for their constituents, which includes everything from enhancing goods, services, systems, and procedures to ensuring that the entire organization is imperative for success. Managing quality is continually chasing excellence: ensuring that everything your organization does is suited for purpose and not only remains so, but continues to improve (What is quality? 2021; What is Quality Management and Why does it matter? 2021). 
Quality control originated with basic inspection systems, in which a business usually hires inspection teams to check, measure, or test items and compare them to a product standard. These would occur throughout all stages of product development, including the design, ongoing research, and delivery. The method was built on investigators separating low-quality items from high-quality products. This is then disassembled, modified, or supplied at a lesser quality. Several results have been obtained (Berry, 1991; Johnson, 1993; Kanji and Asher, 1993; Jabonski, 1994).

If an association's procedures and working population engagement are of excellent quality, it has a better possibility of gaining a sustainable competitive advantage, such as the creation of high-quality goods and a satisfied labor force. The declaration supports a growing view which really, instead of just working independently, sustainability and quality control may function in tandem. When it comes to making long-term lifestyle modifications, concentrating on quality could be the most powerful and compromise approach individuals could do (Relationship Between Quality and Sustainability, 2021; Why Quality Is Important for Sustainability, 2021).

Six Sigma is a relatively modern performance improvement program that is gaining approval and recognition in various sectors as well as service industries throughout the world. Six Sigma fundamentals include Statistical Process Control, Failure Mode Effect Analysis, Gage Repeatability and Reproducibility, and other techniques aimed at reducing rejections and improving quality. Six Sigma provides a fundamental structure within which all of these technologies may be used with managerial support. Though Six Sigma was initially created for production processes, it is now employed by service businesses and service functions in nearly every sector, as well as by some service sectors such as telecommunications and hospitality. Although Six Sigma was initially designed for production processes, it is now utilized by service businesses and service functions in nearly every sector, as well as by some service sectors such as transportation, hospitals, and so on, to enhance profitability and performance. In order to tackle key challenges, they are implementing Six Sigma in their commercial, financial, information systems, administrative, and human resources operations. Thus, under these conditions, Six Sigma methodology has a significant duty to assess key issue areas and developing strong approaches to manage such problems, so improving customer experience (Nonthaleerak and Hendry, 2006; Antony, 2004). Six Sigma also utilizes different quality management (QM) tools and techniques to discover the underlying cause of the problem and to provide process improvement to assist the methodical implementation (Linderman et al., 2003). These instruments and procedures involve the use of an Ishikawa diagram to determine the root cause of an issue, as well as a Pareto analysis to prioritize issues, histograms to examine a process's distribution, and control. Notwithstanding the achievements of Six Sigma at big firms like as General Electric and AlliedSignal Inc., which have established Six Sigma a highprofile corporate phenomenon, its fundamentals have been around for a long time. Motorola invented the official Six Sigma technique. Although other writers claim that Motorola began its Six Sigma quality program in the mid-1960s, the notion of applying Six Sigma procedures was established at Motorola in the 1980s. Their method was founded on strict Japanese TQM theories for use in the manufacturing process, where faults are beautiful just the way and quantify, and therefore deemed suitable to the relatively low, high-precision semiconductor industry with extremely complicated procedures. Motorola's particular participation with Six Sigma commenced in 1982, when it developed a manufacturing-focused quality management program. Motorola's CEO directed his investment bankers to decrease quality expenses in half that year. In 1983, he filed a new accusation. Cost-cutting initiatives have been emerging to highlight to the need for enhanced analytical methodologies and product development for ongoing continuous improvement. The corporation's concentration was on system development, and a variety of advanced quality equipment were used. Following Motorola, the first Six Sigma advocates were Texas Instruments, Allied Signal, Eastman Kodak, Borg-Warner Automotive, GenCorp, Navistar Industrial, and Siebe plc. These Six Sigma pioneers recorded their findings and accomplishments, and other businesses jumped on the bandwagon in the following years. Whereas the stated objective of Six Sigma has been to start concentrating on the production process, it became completely obvious that the proportion, marketing, and customer demand storage capabilities also wanted to concentrate on meeting Six Sigma quality requirements and preventing fraud throughout organization's structure. Motorola eventually built its Six Sigma technologies program and issued Six Sigma practitioner certifications (Smith, 1993; Fortenot et al., 1994; Henderson and Evans, 2000; Nonthaleerak and Hendry, 2006).

Six Sigma originated in practice, but there is a growing body of literature on the subject. Due to the widespread adoption of Six Sigma in business, it is claimed that the academic world would maintain study on this issue in order to assess its underlying concepts, implementation, advantages, and important determining determinants. Charts may be used to track the trends in a process. QM techniques can be utilized in tandem with Six Sigma is being used to improve process performance (Zu et al., 2008; Montgomery and Woodall, 2008; Ur Rehman et al., 2012). The fundamental purpose of this current study is to introduce impressive rules and operations, principally from the service industry and manufacturing industry, in relation to adjustments, as 
well as business areas including such transportation, and to develop a list of specialists and entrepreneurship in incorporating the strategies. It is composed of acquired experiences and achievements. It incorporates lessons acquired from excellent six sigma organizations via quality function deployment, discusses the basics of management level and suitable Six Sigma app implementations, and investigates prospective of Six Sigma methodology enhancements.

\section{LITERATURE REVIEW}

Six Sigma is also more than simply dependability; it is a way of life towards certain professionals. Six Sigma, mostly as principle, helps organizations achieve very low faults per million possibilities over lengthy exposure periods. It refers to a system under which a interpretation, even though it is beyond the limitations and unusual structure. Six Sigma's objective is to optimize processes in order to maximize capacity and minimize heterogeneity, as well as to create and offer quality management for a firm. This technique is a comprehensive and systematic strategy for optimizing operations in various areas of business administration, while also improving managers' administrative abilities, time savings, and boosting cost efficiency (Forest, 2003; Jeannine et al., 2005; Russ et al., 2008; Six Sigma, 2018). Quality Function Deployment (QFD) is a focused approach for carefully listening to the voice of the customer and then reacting to their needs and expectations successfully. QFD is a method and collection of tools for successfully defining customer needs and converting them into precise technical specifications and plans for producing goods that meet those criteria. QFD is used to transform client needs (or VOC) into measurable design objectives and push them down through the assembly, sub-assembly, component, and manufacturing process stages. The QFD approach provides a specified set of matrices that may be used to aid with this process (Quality Function Deployment (QFD), 2021; What Is Quality Function Deployment (Qfd), 2021). These methods are applied for the application of this study.

\subsection{Sigma Methodologies}

Six Sigma refers to the idea and procedures used to reduce faults in their goods, processes, or services. A defect is simply any component that does not meet the customer's specifications. Each step or action in a firm offers a chance for defects to develop, and six-sigma programs aim to decrease variance in the processes that contribute to these faults. Variation is viewed as the adversary of quality by Six Sigma supporters, and much of the philosophy underpinning Six Sigma is committed to dealing with this issue. The Six Sigma methodology guarantees that faults and issues inside the system are significantly reduced. Six Sigma also aids us in identifying and measuring issues. Six Sigma likewise assists everyone in addressing issues and the actions that may be used to eliminate these difficulties or faults. With the formulation of objectives and aspirations, Six Sigma methodology and important patterns methodologies enable continual improvement and reject minimization. Six Sigma would be implemented through with a succession of successful initiatives in the service industry. Transformational Quality Management Project: a project to enhance a commercial operational process spanning spans an enterprise, such as customer orders, stock management, and customer care. Traditional Quality Improvement Project: focused at resolving persistent issues in an organization's numerous operations. Conventional Training Program: focused at resolving persistent problems that straddle several organizational activities. Design for Six Sigma Project: a project aiming at combining the voice of the customer (i.e. the requirements of the customer) and Six Sigma stage goals into the manufacturing of goods, services, or activities in order to improve quality (Forrest, 2003; Anbari and Kwak, 2004; Anbar, 2004; Kwak and Anbari, 2006).

Six Sigma is a critical performance management method which is based on client needs, quality management, quantitative accuracy, and implementation. It is a ruthlessly efficient approach and strategy that still gives the capabilities necessary to produce consistent, high-performance results from procurement practices. Six Sigma helps types of firms to make shareholder, content choices that lead to a reduction overall quality problems, higher revenues and employee satisfaction, and increased goods by accelerating progress and lowering variance. Six Sigma techniques comprise a customized design that has been shown to drive and achieve transformative change inside an organization. The utility package includes a number of templates for measuring, gathering, and reporting information, as well as producing diagnostic tools. This technique and technologies could be used for process analysis, measurement, improvement, and management. Six Sigma specifies and assesses the chances for mistake and counts faults in the same spot every time via utilizing a universal measuring instrument, providing a method for evaluating improvements. Six Sigma technique combines and applies this data and statistical analysis into a development framework, allowing organizations to make an informed decision of where and how to include it (Anbari and Kwak, 2004; Kwak and Anbari, 2006).

Sustainable needs, international competitiveness, and regulatory frameworks on global warming have compelled companies to embrace sustainable methods. Green Lean Six Sigma (GLS) is an eco-friendly strategy that reduces carbon footprints while 
producing high-quality goods. However, in order to implement the GLS program, it is necessary to blend individual Green, Lean, and Six Sigma techniques into the unique GLS methodology. Furthermore, there is no GLS framework that can be used regardless of the size, kind, or culture of the company. As a result, the current effort involves the integration and improvement of the GLS infrastructure. The main limitation of the present research work is that the GLS framework has not tested pragmatically. This limitation provides the impetus for future research to implement GLS in different industrial sectors. Future research can also focus on the role of GLS for sustainability enhancement through industry 4.0 and modeling and investigation of GLS barriers (Kaswan and Rathi, 2020). Given the widespread adoption of Six Sigma programs, there is significant concern about serious shortcomings. One of the reasons many Six Sigma initiatives fail is a deficiency of a successful implementation for successfully guiding the execution of these programs. The goal of this research is to create an effective six-step implementation strategy based on a successful Six Sigma program in a Network Technology firm. The first stage is to conduct a strategic analysis that is influenced more by marketplace and the consumer. The next stage is to form a high-level, cross-functional team to spearhead the development plan. The third stage is to find tools for general improvement. The fourth stage is to undertake higher processing modeling and select areas that need improvement. The fifth stage is to create a comprehensive plan for lowlevel improvement teams, followed by the sixth step of implementing, documenting, and revising as appropriate. Essential for both practitioners and researchers, we discuss the consequences of the requirements gathering as well as potential future research initiatives (Chakravorty, 2009).

Figure 1: Concept of Define, Measure, Analyse, Improve, Control (DMAIC)

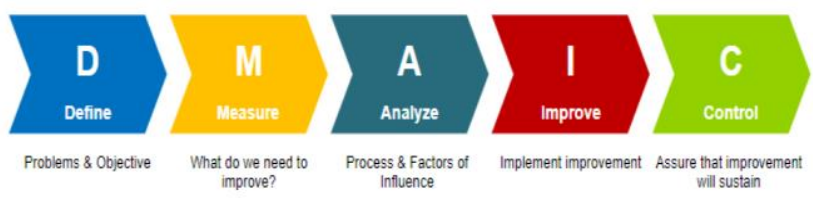

Soruce: What is DMAIC? https://online.visual-paradigm.com/cn/knowledge/six-sigma/what-is-dmaic/, Acess Date: 15.05.2021)

Phases of Six Sigma Development: The Six Sigma improvement approach is divided into five stages: define, measure, analyze, improve, and control. The definitions of these phases as below (Anbari and Kwak, 2004; Kwak and Anbari, 2006; Brady and Allen, 2006; Define-Measure-Analyze-Improve-Control (DMAIC), 2021; What is DMADV, Define-Measure-Analyze-ImproveControl (DMAIC), 2021; see Figure 1);

Define Phase 1: who the customers are and what their priorities are? During the Define phase, the Black Belt assembles the team, which includes people from several departments impacted and influenced by the problem. The team defines the issue precisely and assesses its financial and quality effect on the organization. The team develops metrics to analyze the effect of the problem in the past, as well as to document progress as the problem is resolved.

Measurement Phase 2: How is the process measured and how is it performing? During the Measure phase, the Black Belt team researches and examines the problem's methodology and metrics. The team creates process maps and assesses measuring system accuracy and precision. The team creates new measures. Using a number of techniques, the team determines key probable sources of the problem.

Analyze Phase 3: What are the most common sources of defects? During the Analyze phase, the Black Belt team identifies the key issues that are causing the problem. They use a range of statistical techniques to test hypotheses and experiment with the process in this manner. Once the team understands the link between the causes and effects, they can decide how to accelerate the efficiency and how much advantage to estimate from the modification.

Improve Phase 4: How can we eliminate the sources of the defects? The Black Belt team performs improvements to enhance performance metrics during the Improve phase. The assessment includes the approach to confirm the predicted performance by using measurements that have already been delivered and applied.

Control Phase 5: Why should designers sustain the gains? The Black Belt organization gets and synthetic composites to reduce and improve on future forecast errors during the Control phase. Derived from primary or statistical process approaches are examples of such methods. This critical step ensures that the same issue would not reoccur in the future.

The basic stage is to do a research review to determine the existing studies and implementation of Six Sigma in the process 
industry. According to the literature review, majority Six Sigma research has indeed been done in manufacturing sectors, but there is space for interpretation in industrial processes by the use of Six Sigma approach. Basic tools of DMAIC, typically used at the yellow-belt level of competence include flowcharts, check sheets, Pareto diagrams, cause/effect diagrams, scatter diagrams, histograms and statistical process control. More advanced tools such as regression analysis (with indicator variables, curvilinear regression and logistic regression), hypothesis testing, control charts and design of experiments typically feature at the blackbelt level. This also means Six Sigma may be viewed as a combination of existing tools and techniques available well before Motorola developed this approach (Ferrin et al., 2002; Brady and Allen, 2006; Kwak and Anbari, 2006; Van Iwaarden et al., 2008).

\subsection{Quality Function Deployment (QFD) Methodology}

Quality function deployment (QFD) methodology has been successfully utilized to transform client requests into architectural or professional features in a variety of industries. QFD is a comprehensive framework for quantitatively considering customer requirements and manufacturing capabilities so that a product's or service's target specifications are in accordance with what consumers anticipate (Trappey et al., 1996; Gunther, 2000; Björlin and Edvardsson, 2003). Customer and design needs are prioritized by employing group consensus approaches in the QFD methodology, which enables a decision-making framework for studying solutions based on consumers' real requests (Gunther, 2000; Natee et al., 2016). The goal of this research is to create an interval-valued intuitionistic fuzzy QFD technique for public transportation to satisfy consumer expectations and service aspects that are unclear. This technique allows for a better understanding of the link between various passenger expectations and the technological needs that go along with them. To determine the current satisfaction ratings and significance weights associated with each consumer demand, a customer satisfaction survey is employed. Completing the House of Quality and calculating the significance weights for each technical need allows you to concentrate on the most important aspects (Natee, Low and Teo, 2016; Gunther, 2000).

House of Quality is a six-part matrix (Cohen, 1995). This methodology's descriptions of these sections are represented in the following order: (1) Customer voice for identifying consumer needs, requests, and perceptions from the company; (2) Technical requirements for taking necessary actions to enhance the reliability of its business; and (3) Customer evaluations (Planning matrix) where current customer satisfaction principles, directed consumer satisfaction values, challenge existing, and the impact on customer satisfaction of each consumer demands are mentioned. (5) A matrix to demonstrate the orientation of the association involving technical needs and consumer feedback. (6) Technical requirement ratings, which have been derived as objective and subjective significance ratings utilizing customer needs weighting factors and a fuzzy connection.

Public transport of harmful chemicals (hazmats) has remained a source of worry resulting in significant risks it presents to health and the environment. This study provides a new and moderately recommendation foundation for hazmats transport infrastructure risk assessment based on a combination of quality function deployment (QFD), fuzzy analytic hierarchy process (FAHP), fuzzy failure mode and effect analysis (F-FMEA), and variational optimization techniques. The QFD is creatively utilized to build the entire architecture, including includes five basic components of generalized risk assessment: risk analysis and risk, risk evaluation, and controlling risks. The F-AHP is often used to create a hierarchical assessment instrument and to rate the relevance of each cost component. The F-FMEA is used to assess the possible hazards of prevention strategies and to calculate the risk prediction coefficient for each performance metric, which is then utilized to alter the confidence interval fulfillment level in the nonlinear objective scheduling algorithm. The discriminant analysis is offered as a useful technique for dealing with the inherent unstructured situations in the risk assessment process. To show the efficacy and practicality of the suggested technique, an observational example on risk assessment of a hazmats transporting firm is provided. Findings of the study, several future recommendations for risk assessment in hazardous transportation system are presented (Li, et al., 2019).

A collaborative design concept integrating analytic hierarchy process (AHP) with quality function deployment (QFD) in combined application with cost factor measure (CFM) has been defined to evaluate and then then choose candidate-suppliers within a business model under numerous different, contrasting requirements surroundings. The engineering and consumer objectives that will determine the selection choice have been defined. The multilevel QFD technique enables the decision - makers (DM) to evaluate candidate-suppliers by taking into account both CFM and quantitative measurements. The suggested methodology's responsiveness is investigated using a metric known as impartial component judgement weight. The centralized QFD technique enables the decision maker (DM) to evaluate applicants by taking into account both CFM and quantitative measurements. The suggested methodology's sensitivity is investigated using a metric known as objective factor decision weight. The developed approach was evaluated using the database from Yahya and Kingsman (1999). Liu and Hai (2005) used the same datasets to 
examine their model. A design of experiment comparison analysis was used to evaluate the efficiency of the developed structured collaborative design method.

The goal of Deveci et al. (2019)'s research is to create a quantitative evaluation system for public transportation operations to translate customer expectations into service quality requirements. A customer satisfaction survey is used as an input to assess the degree of service quality in a public transportation operator in order to determine passenger requests. First, Principal Component Analysis (PCA) is used to minimize the number of client satisfaction requirements, and then Quality Function Deployment is used to identify the assessment variables (QFD). This method uses interval-valued fuzzy soft QFD to synthesize consumer and engineering graduates. The findings demonstrate that the proposed technique aids public transportation operators in focusing on high-priority regions so that resources may be efficiently deployed to meet people's transportation systems.

Satisfied customer in public transportation is critical for understanding and analyzing customers' needs and expectations (Eboli and Mazzulla, 2007). To improve service quality, consumer-oriented service design relies on converting client expectations into service design characteristics. In the public transportation industry, it is critical to meet the needs of consumers or passengers in terms of specific quality criteria such as frequency, convenience, and safety. In such situation, a system for translating passenger expectations into quality standards is required.

The research of Carnevalli et al. (2010) tries to bridge these gaps by presenting an incorporated organizational policy fuzzy QFDMADM approach that integrates QFD, Analytic Hierarchy Process (AHP), Decision-Making Trial and Assessment Experiment (DEMATEL), and Analytic Network Process (ANP) with fuzzy set theory. To exemplify the suggested technique, a research paper in the Philippine meat processing sector was used. The case research findings highlight the critical decision criteria for all processes, which will be used as inputs by project managers. With exception of earlier models, the proposed methodology retains the changeover of the priority flow as well as all four project management processes. As a result, business requirements are incorporated into all project implementation phase, indicating that these expectations are handled at each level. Furthermore, the suggested framework addresses the ambiguity and underlying complexity of interdependencies among decision criteria in the four stages of product development processes. The suggested paradigm adds to the literature on sustainable product development in a thorough and analyzing the structure (Carnevalli et al., 2010; Ocampo et al., 2020).

Combining sustainable growth with management, and collecting objectives from its three aspects (economic, environmental, and social) generated from consumer and stakeholder requirements, has been identified as a possible source of competitive advantage for businesses. In recent years, there has also been a considerable rise in academic and business interest in sustainable supply chain (SSC) management. This article looks at the components and parts of SSC monitoring and how they may be used to build an assessment framework. A successful SSC organization may be produced by employing quality function deployment (QFD) as a customer planning and enhancement mechanism. QFD employs a matrix known as the "House of Quality" (HoQ), and building the HoQ is an important stage in the implementation of QFD since it converts client needs into technical qualities. Participants in $\mathrm{HoQ}$ construction sessions, on the other hand, focus on providing information about their unique judgements in a variety of formats, such as quantitatively or verbally, relying on their understanding, background, society, and context. Moreover, they might produce inconsistencies in judgments that are difficult to measure consistently. As a result, the goal of this study is to apply an enlarged QFD research methods in SSC through developing a new decision-making process strategy which incorporates different preference configurations and incomplete information into account and fuses differential expression configurations into one homogeneous decision maker using fuzzy set theory. A research performed at HAVI Logistics-Turkey is indeed provided in the article to evaluate the validity of the suggested technique (Büyüközkan and Çifçi, 2013). The study of Akkawuttiwanich and Yenradee (2018) offers a theoretical suggestion for a conceptual model of QFD application that aims to reduce the challenges associated with its implementation. The various phases were completed to establish this model: an annotated bibliography to recognize information about QFD use, a discussion of the findings in a field study and an evaluation of obtained from various interviews with QFD customers, through the use of AD (Axiomatic Design) to improve the conceptual framework using findings from the research stages.

\subsection{Issues in Service and Manufacturing Sectors}

According to research, the majority of service procedures, such as payment processing, billing, accounting, transportation, inventory management, responsiveness to service inquiries, security checks, and so on. If we raise the sigma quality level of any of the above-mentioned service processes to four sigmas, the defect rate will fall. This obviously implies that process 
performance has improved. The yield of the procedure will be raised. This might result in large economic advantages to the business model of any making decisions in powerful quality management techniques along with Six Sigma (owing to lower number of defects, sub - national of consumer complaints, improved customer satisfaction, and so on). Many transaction businesses nonetheless believe that Six Sigma is only for industrial enterprises. The three fundamental concepts of statistical thinking are the most effective method to persuade a service-oriented organization to begin, establish, and apply a Six Sigma plan. Because of the unique characteristics of the service industry, Six Sigma initiatives face unique obstacles. The next phase would be to look for answers to these classification problems. These are listed as below (Anbari and Kwak, 2004; Kwak and Anbari, 2006; Brady and Allen, 2006; Montgomery and Woodall, 2008):

i. High levels of consumer satisfaction: Most companies have service functions as an important component of their operations. The incorporation of service operations into a company organization results in a completely new mindset and attitude. Due to a massive focus on client requirements and opportunity to engage from other consumers, a service company behaves differently. Service offers are felt considerably sooner than items, which are sometimes kept in a warehouse: The consumer is having issues after the service has been provided. The issues in service are different since these problems must be handled quickly.

ii. Different client requirements: Consider scheduling are made up of specific transactional and engagement elements. The transaction portion suggests that the output of high-volume operations is more process dependent. Fast food restaurants, direct mail, financing, health care, telecommunications, insurance, and tickets are examples of such sectors. For the consequences of low-volume, moderate services, these relationship elements necessitate greater personal respect and concern. Sit-down restaurants, customized health care, and more customized services are examples of such businesses. Transaction activities are anticipated to be supplied quicker, better, and at a lower cost, whereas engagement interactions are supposed to be delivered effectively.

iii. Relatively unexpected volumes: One of the most difficult difficulties for adopting any quality instruments in the service sector is an unexpected volume. Consequently, in this part, concentricity and measurement rejections are used to anticipate consumer dispersion, yet every prediction has mistakes.

iv. Unpredictability of tasks: In manufacturing plants, each process is fixed and clear, but in service sectors, there are many tasks that must satisfy customers and meet varying needs, resulting in unexpected ineluctability jobs.

v. Absence of competent information concerning quality: Though commodities are handled between various stations in manufacturing sectors, data and information may also be conveniently transferred and analyzed. When compared to service sectors, the spectrum of products is frequently consistent and the variety of output is smaller. As a result, manufacturers collect data from their established procedures and activities, and then they face different types of information availability challenges.

vi. The following are the fundamental reasons of these issues: (1) a shortage of knowledge (2) rapid variation and evolving economic plan (3) Difficulty defining and analyzing performance measures and variables (4) Significantly influenced by consumer preference.

vii. Deficiency of a well-established successful implementation: Controlling and seeking advice is also an essential component of any organizational change. As a result of this lack of patient satisfaction and variables, the created quality program results in lower Six Sigma efficiency. Many articles have been written regarding the key elements for Six Sigma deployment. A better awareness of customer requirements and expectations, particularly those crucial operational performance qualities have the biggest influence on organizational commitment. As a result, the expenses of policing and misguided problem-solving attempts with no organized or disciplined approach might be greatly reduced.

The main goal of this research is to present outstanding policies and procedures mostly from service sector and manufacturing industry in direct proportion to changes, as well as business sectors such as transportation and guide the choice, which are experts and entrepreneurial activities in implementing the methodologies. It is made up of experience gained accomplishments. It includes the ideas learned from great six sigma businesses via quality function deployment, addresses the fundamentals of management position and appropriate Six Sigma application deployment, and explores potential Six Sigma technique improvements. 


\section{DATA AND METHODOLOGY}

Customers Voice in Application for Service/Manufacturing Industry: Quality Function Deployment (QFD) is a total quality management (TQM) delivery approach that requires a straightforward evaluation of client/end-user requirements in addition to the specific needs of a project in order to turn them into design goals. QFD is just one of the strategies for dealing with consumer demands and desires quite consistently in order to achieve a construction company's most critical goal, client satisfaction. QFD deals with requirements of clients and expectations more consistently for providing the most significant objective of a business, enjoyment of customers. QFD is generally a cumulative quality management (TQM) application technique requiring clear evaluations of client/end-user anticipations separately from the basic needs of a research to modify them into design objectives (Bossert, 1990; Franceschini, 2001; Maritan, 2015).

In this part of the research, a quality function deployment (QFD) was implemented in this component of the analysis to obtain assessment of supply chain in terms of management, satisfaction, with the consumer and business expectation for the furniture manufacturers-producers in manufacturing industry. This application was evaluated via QFD and Six Sigma due to Customer Satisfaction together for manufacturing/service industry in Turkey via a survey. This survey was e-mailed to approximately a total of 140 companies of service Industry (supplier/transportation) in Turkey with the help of the Turkish Industrialists' and Businessmen's Association (TUSIAD) and Turkey Exporters Assembly (TIM). The results of this questionnaire were assessed on the framework of sustainability via customer satisfaction The sample size was 91, returning the survey from these companies in Turkey, with approximately a $67 \%$ rate of response. The goals of a firm might differ from one to the next. Reducing service costs, increasing competitiveness, lowering sales costs, improving global prediction, and increasing brand loyalty are some instances of applicable goals. In accordance with customer expectations, the key goals are as follows (Voice of Customers-Whats) for service industry and production sector are shown in Table 1.

Table 1: Voice of Customers Criteria - Whats

\begin{tabular}{|cl|}
\hline$\checkmark$ & $\begin{array}{l}\text { Collaborating with colleagues throughout the organization and a large number of contributors to deliver and present } \\
\text { excellent customer service. }\end{array}$ \\
\hline$\checkmark$ & Provide assistance to clients through a full range of communication techniques. \\
\hline$\checkmark$ & Methods for assessing consumer preferences and combining business, technological, and cognitive strategies \\
\hline$\checkmark$ & Supplying for the basic necessities of people about delivering of the desired accuracy \\
\hline$\checkmark$ & Organization Strategic processes, including the automation of core business processes (marketing, sales, service). \\
\hline
\end{tabular}

Technical Criteria (tc) of customer voice for Service/Production Sector-Industry are shown in Table 2 as below. This table is prepared from interviews of the manufacturers-service providers, reports of these businesses, literature resources and experts of these industries.

Table 2: Technical Criteria of Customer Satisfaction (Customer Voice) for Service/Production Industry

tc1. Strategic operations including the automating of fundamental company operations (marketing, sales, service).

tc2. Approaches for evaluating customer behavior and integrating commercial, technical, and intellect tactics.

tc3. Support individuals using various communication methods.

tc4. Make participants across organizational colleagues and numerous collaborators to provide high quality customer service and follow-up.

tc5. Required, assist with the incorporation of various apps and/or databases.

tc6. Digital repository and resource management capability for compiling and disseminating inventories from disparate data sources throughout an enterprise

tc7. Decrease the number of special assessments

tc8. Decrease the number of clarifying calls

tc9. Start steps to verify that purchases are approved for processing when they are delivered.

tc10. Allow for real-time modifications to manufacturing system and price in response to manufacturing modifications

tc11. Provide team members with tools to help them convert quotations into transactions more quickly.

tc12. Utilize automation to efficiently route create and sell and marketing inquiries.

tc13. Prioritizing numerous price alternatives to significant milestone, comprehensive, comparable, and legitimate quotations. 
The quality function deployment applied from the feedbacks of customers and director of Corporation-business of Turkey and interviews with experts of the corporation of service/manufacturing sector- industry in Turkey are shown in Table 3

Table 3 provides the interrelationship matrix with the type of relationships. Any cell that is empty implies no or insignificant relationship. The degrees of the strength of relationship are placed in the column of customer requirements and technical characteristics of quality function deployment matrix.

Table 3: Quality Function Deployment Table

\begin{tabular}{|c|c|c|c|c|c|c|c|c|c|c|c|c|c|c|c|}
\hline \multirow{2}{*}{ 氙 } & \multirow{2}{*}{ 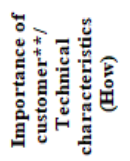 } & \multicolumn{13}{|c|}{ Technical Criteria } & \multirow{3}{*}{$\begin{array}{c}\mathrm{G} \\
\mathrm{e} \\
\mathrm{n} \\
\mathrm{e} \\
\mathrm{r}\end{array}$} \\
\hline & & $\mathrm{tc1}$ & $\mathrm{tc} 2$ & $\mathrm{tc} 3$ & tc4 & tc5 & tc6 & tc 7 t & tc\& & tc9 & tc10 & $\mathrm{tc} 11$ & $\mathrm{tc} 12$ & $\operatorname{tc} 13$ & \\
\hline $\begin{array}{l}\text { Provide assistance to clients through a full range of } \\
\text { communication techniques.e }\end{array}$ & 4 & 3 & 9 & 3 & 9 & 9 & 3 & 9 & 3 & 3 & 9 & 3 & 9 & 9 & \\
\hline $\begin{array}{l}\text { Collaborating with colleagues throughout the organization } \\
\text { and a large number of contributors to deliver and present } \\
\text { excellent customer service. }\end{array}$ & 4 & 1 & 9 & 9 & 9 & 9 & 3 & 9 & 3 & 3 & 9 & 9 & 3 & 9 & 1 \\
\hline $\begin{array}{l}\text { Methods for assessing consumer preferences and } \\
\text { combining business, technological, and cognitive } \\
\text { strategies }\end{array}$ & 4 & 9 & 3 & 3 & 9 & 3 & 3 & 3 & 3 & 9 & 9 & 9 & 3 & 9 & $\begin{array}{l}\mathrm{T} \\
0 \\
\mathrm{t}\end{array}$ \\
\hline $\begin{array}{l}\text { Supplying for the basic necessities of people about } \\
\text { delivering of the desired accuracy }\end{array}$ & 5 & 3 & 3 & 3 & 9 & 9 & 3 & 9 & 3 & 3 & 9 & 9 & 9 & 3 & 1 \\
\hline $\begin{array}{l}\text { Organization Strategic processes, including the } \\
\text { automation of core business processes (marketing, sales, } \\
\text { service). }\end{array}$ & 5 & 3 & 3 & 3 & 3 & 3 & 9 & 1 & 9 & 9 & 3 & 3 & 9 & 9 & \\
\hline Absolute Net Weight (MA) & & 82 & 114 & 90 & 168 & 144 & 96 & 134 & 96 & 120 & 168 & 144 & 150 & 168 & 1674 \\
\hline $\begin{array}{l}\text { Customer Requirement Net } \\
\text { Weight (MGA) }\end{array}$ & & 4,90 & 6,81 & 5,38 & 10,04 & 8,60 & 5,73 & 8,00 & 5,73 & 7,17 & 10,04 & 8,60 & 8,96 & 10,04 & 100,00 \\
\hline Rank & & 13 & 9 & 12 & 1 & 5 & 10 & 7 & 10 & 8 & 1 & 5 & 4 & 4 & 18 \\
\hline
\end{tabular}

Table 4: The groups of the priority order for the Technical Requirements

\begin{tabular}{|c|c|c|}
\hline The priority number-importance (Rank) & CNW-percentage value & Technical requirements \\
\hline $1(3)$ & 10,04 & tc4; tc10; tc13 \\
\hline $2(4)$ & 8,96 & tc12 \\
\hline $3(6)$ & 8,60 & tc5; tc11 \\
\hline $4(7)$ & 8,00 & tc7 \\
\hline $5(8)$ & 7,17 & tc9 \\
\hline $6(9)$ & 6,81 & tc2 \\
\hline $7(11)$ & 5,73 & tc6; tc8 \\
\hline $8(12)$ & 5,38 & tc3 \\
\hline $9(13)$ & 4,90 & tc1 \\
\hline
\end{tabular}

As a result of this sorting, 3 units of technical characteristics (tc4; tc10; tc13) which are the first priority, were identified with a value of 10.04 percent; The second priority technical characteristic includes 1 unit of technical characteristics (tc12) which was identified with a value of 8,96 percent, the third priority technical characteristic involves 2 unit of technical characteristics (tc5; tc11) which were identified with a value of 8.60 percent, so on (see Table 4). Table 4 is presented the groups of the priority order for the technical requirements depending on the sorting rank values from Quality Function Deployment Table.

A Pareto Diagram is a diagram which sorts the classifications, thus they are rank-sorted from the highest total occurrences to the lowest. In prioritizing the technical requirements, PA technique supports to determine the top $20 \%$ of causes those 
requirements to be addressed to resolve the $80 \%$ of the problems. The Absolute Weights (AW) variables of the technical requirements which are evaluated for each technical characteristic acquired that eliminate in the biggest weight classified. While assessing the greatest-priority absolute weights verified requirements between the values of these requirements in PA, conformity with $80 \%$ threshold risk variable, the initial 20 requirement-failure point sources prominence. The pareto diagram is used to demonstrate processions of problems or necessities in decreasing order (see figure 2 ).

\section{Figure 2: Pareto Evaluation Chart}

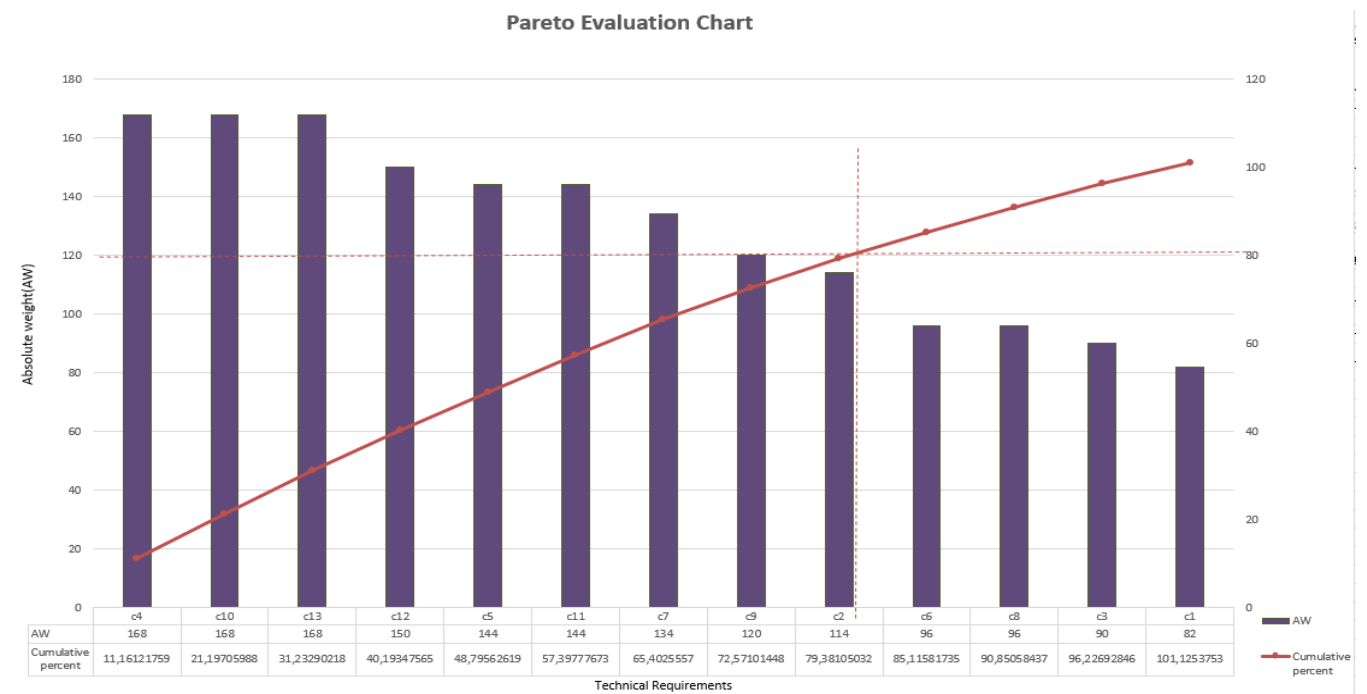

The Absolute Weights (AW) variables of the technical requirements which are evaluated for each technical characteristic acquired that eliminate in the biggest-highest weight classified. While assessing the greatest-priority absolute weights verified requirements between the values of these requirements in PA, conformity with $80 \%$ threshold risk variable, the initial 9 requirement-failure point sources prominence. The AW values may be shown in a Pareto diagram to show which technical criteria are most essential, as well as the risk priority of features in satisfying customer needs. During the evaluation of the highpriority absolute weights supported requirements point sources between the values of these criteria in PA, conformance with the 80 percent threshold risk variable, the initial 9 failure point sources prominence. The absolute weight values can be arranged into a Pareto diagram to demonstrate which technical features are more essential and the risk priority of requirements in satisfying customer needs (see Figure 2).

Several suggestions for increased comfort and client satisfaction:

1. Employee cooperation is critical, especially in this industry, where the entire firm is dependent on good feedback and overall satisfaction from consumers, despite the fact that so many other options are readily available.

2. The employees at the contact centre should always be sufficiently prepared so that they would adequately interact with clients due to differing concerns. The reaction time to consumer concerns should just be reduced to a minimum.

3. Appropriate instruction had been required for both new and current clients. This would increase client happiness and utilization of the business.

4. Consumer service care providers ought to be accessible for advice and assistance; this increases customer faith in the center's dependability and improves customer experience.

5. Guest service centers may use six sigma strategies to overcome current employees and recruit new ones. This would not only enhance their procedure, but it would also result in a large potential customers and economic advantages. 
Six-sigma has shown to be a significant and successful instrument in the automotive industry for lowering rejecting rates and increasing throughput. More such examination of these issues revealed that the successful execution of Six Sigma in the service and/or manufacturing industry necessitates not just good corporate strategy, but also customer requirements and satisfaction, which should be evaluated and incorporated into the successful implementation.

\section{CONCLUSION}

Many of the most significant constraints in this sector is the challenge in measuring and obtaining data from manufacturing systems and service businesses, because these firms do not discuss appropriate information or quality programs. The platform's performance should be defined and measured through establishing quality goals and priorities. Qualified and highly that are concentrated on certain possibilities should be effectively created.

In the service/manufacturing industry, the customer satisfaction is an important aspect. So, in order to properly apply Six Sigma in the service industry, corporate processes and consumer needs should be examined. One of the distinctions is the use of the DMAIC (Define, Measure, Analyze, Improve, and Control) process to a telecom enterprise. As previously said, numerous service providers lack a reasonable contemplation toward customers and relevant qualifying data. This is an unique approach to six sigma stages that takes into account consumer and development skills in the service/manufacturing industry.

Several suggestions for increased comfort and client satisfaction:

1. Employee cooperation is critical, especially in this industry, where the entire firm is dependent on good feedback and overall satisfaction from consumers, despite the fact that so many other options are readily available.

2. The employees at the contact centre should always be sufficiently prepared so that they would adequately interact with clients due to differing concerns. The reaction time to consumer concerns should just be reduced to a minimum.

3. Appropriate instruction had been required for both new and current clients. This would increase client happiness and utilization of the business.

4. Consumer service care providers ought to be accessible for advice and assistance; this increases customer faith in the center's dependability and improves customer experience.

5. Guest service centers may use six sigma strategies to overcome current employees and recruit new ones. This would not only enhance their procedure, but it would also result in a large potential customers and economic advantages.

Six-sigma has shown to be a significant and successful instrument in the industry for lowering rejecting rates and increasing throughput. More such examination of these issues revealed that the successful execution of Six Sigma in the service and/or manufacturing industry necessitates not just good corporate strategy, but also customer requirements and satisfaction, which should be evaluated and incorporated into the successful implementation. Its business perspective, in especially, would promote trust purpose of growing are concentrated on addressing with these same operations that have an effect on the consumer. As a consequence, the overall effect of it assisting in raising quality in service and manufacturing sectors would be larger. At first sight, the service and manufacturing sectors appear to be essentially competitive via Six Sigma implementations. Resource management, customer satisfaction, evaluating product quality and program management, and optimizing service/manufacturing industry payback.

The much more essential aspect for merging the Six Sigma and service and manufacturing sectors is procedure management, quality enhancement, relating to construction work of existing processes advancement, and optimizing the payback of service businesses along identifying the highest level of satisfaction.

Six Sigma is one major method that provides monetary incentives to the service industry by assisting businesses in adopting best practices for policy implementation through a quality procedure that ensures its success. Its business perspective, in especially, would promote trust purpose of growing are concentrated on addressing with these same operations that have an effect on the consumer. As a consequence, the overall effect of it assisting in raising quality in service and manufacturing sectors would be larger. At first sight, the service and manufacturing i sectors appear to be essentially competitive via Six Sigma implementations. Resource management, customer satisfaction, evaluating product quality and program management, and optimizing service/manufacturing industry payback. The much more essential aspect for merging the Six Sigma and service and 
manufacturing sectors is procedure management, quality enhancement, relating to construction work of existing processes advancement, and optimizing the payback of service businesses along identifying the highest level of satisfaction.

\section{REFERENCES}

Akkawuttiwanich, P. and Yenradee, P. (2018). Fuzzy QFD approach for managing SCOR performance indicators. Computers \& Industrial Engineering, 122, 189-201. doi:10.1016/j.cie.2018.05.044.

Anbari, F. T. and Kwak, Y. H. (2004). Success Factors in Managing Six Sigma Projects, Project Management Institute Research Conference, London, UK, England. Newtown Square, PA: Project Management Institute, July 11-14, 2004 https://www.pmi.org/learning/library/successfactors-managing-six-sigma-projects-8293

Antony, J. (2004). Six-Sigma in the UK Service Organizations: Results from a Pilot Survey, Managerial Auditing Journal, 19 (8), $1006-1013$.

Berry, T. H. (1991). Managing the Total Quality Transformation, McGraw-Hill, First Edition, USA.

Brady, J. E. and Allen, T. T. (2006). Six Sigma Literature: A Review and Agenda for Future Research. Quality and Reliability Engineering International, 22(3), 335-367. doi:10.1002/qre.769.

Björlin, L., S. and Edvardsson, B. (2003). Customer expectations on service guarantees. Managing Service Quality: An International Journal, 13(5), 338-348. doi:10.1108/09604520310495822

Bossert, J.L (1990). Quality Function Deployment: The Practitioner's Approach (Quality and Reliability Series, Volume 21), CRC Press, 125 p., ISBN 13: 9780824783785

Büyüközkan, G. and Çifçi, G. (2013). An integrated QFD framework with multiple formatted and incomplete preferences: A sustainable supply chain application. Applied Soft Computing, 13(9), 3931-3941. doi:10.1016/j.asoc.2013.03.014

Carnevalli, J. A., Miguel, P. A. C. and Calarge, F. A. (2010). Axiomatic design application for minimising the difficulties of QFD usage. International Journal of Production Economics, 125(1), 1-12. doi:10.1016/j.ijpe.2010.01.002

Chakravorty, S. S. (2009). Six Sigma programs: An implementation model. International Journal of Production Economics, 119(1), 116. doi:10.1016/j.ijpe.2009.01.003

Cohen, L. (1995). Quality function deployment: How to make QFD work for you. Prentice Hall.

Gunther, D. (2000). Quality Function Deployment - How to Make QFD Work for You. Insight, 3(2), 55-56. doi:10.1002/inst.20003255, Book Reviews.

Define-Measure-Analyze-Improve-Control (DMAIC), https://cdn.ttgtmedia.com/searchSoftwareQuality/downloads/ect01TreasurechestSixSigma.pdf ,13-27 pp. (Access Date: 12.03.2021).

Deveci, M., Öner, S. C., Canıtez, F. and Öner, M. (2019). Evaluation of service quality in public bus transportation using interval-valued intuitionistic fuzzy QFD methodology. Research in Transportation Business \& Management, 100387. doi:10.1016/j.rtbm.2019.100387

Eboli, L. and Mazzulla, G. (2007). Service Quality Attributes Affecting Customer Satisfaction for Bus Transit. Journal of Public Transportation, 10 (3), 21-34. http://doi.org/10.5038/2375-0901.10.3.2

Ferrin, D., Muthler, D. and Miller, M. (2002). Six Sigma and simulation, so what's the correlation? Proceedings of the 2002 Winter Simulation Conference. IEEE Press: Piscataway, NJ, 1439-1443.

Forrest W. Breyfogle (2003). Implementing six sigma: smarter solutions using statistical methods, Second Edition, John Wiley and Sons., 1231 p., ISBN 13:9780471265726.

Fortenot, G., Behara, R. and Gresham, A. (1994). Six Sigma in customer satisfaction, Quality Progress, December, 27(12), 73-76.

Franceschini, F. (2001). Advanced Quality Function Deployment, First Edition, CRC Press, 209 p., ISBN 13: 9781574443219.

Henderson, K. M. and Evans, J. R. (2000). Successful implementation of Six Sigma: benchmarking General Electric Company. Benchmarking: An International Journal, 7(4), 260-282. doi:10.1108/14635770010378909

Jabonski, J. R. (1994). Implementing TQM: Competing in the 90s Through Total Quality Management, 2nd Second Edition, Michigan USA, ISBN13: 978-1878821034, $224 \mathrm{p}$.

Jeannine S., Penn M. L. and Erin H. (2005). Relationships Between CMMI and Six Sigma, Technical Note CMU/SEI-2005-TN-005 report number.

Johnson, R. S. (1993). Management Processes for Quality Operations, Milwaukee, WI: ASQC Quality Press, USA. 
Kanji, G.K. and Asher, M. (1993). Total Quality Management process, -a systematic approach, Advances in Total Quality Management Series, 4, Carfax Publishing, Abingdon.

Kaswan, M. S. and Rathi, R. (2020). Green Lean Six Sigma for sustainable development: Integration and framework. Environmental Impact Assessment Review, 83, 106396. doi:10.1016/j.eiar.2020.106396.

Kwak, Y. H. and Anbari, F. T. (2006). Benefits, obstacles, and future of six sigma approach. Technovation, 26(5-6), 708715. doi:10.1016/j.technovation.2004.10.003.

Linderman, K., Schroeder, R.G., Zaheer, S. and Choo, A.S. (2003). Six Sigma: a goal-theoretic perspective, Journal of Operations Management, 21(2), 193-203.

Li, Y.-L., Yang, Q. and Chin, K.-S. (2019). A decision support model for risk management of hazardous materials road transportation based on quality function deployment. Transportation Research Part D: Transport and Environment, 74, 154-173. doi:10.1016/j.trd.2019.07.026.

Liu, F.-H. F. and Hai, H. L. (2005). The voting analytic hierarchy process method for selecting supplier. International Journal of Production Economics, 97(3), 308-317. doi:10.1016/j.ijpe.2004.09.005.

Maritan, D. (auth.) (2015). Practical Manual of Quality Function Deployment, Springer International Publishing, First Edition, 199 p., ISBN 13:9783-319-08521-0

Montgomery, D.C. and Woodall, W.H. (2008). An Overview of Six Sigma, International Statistical Review, 76, 3, 329-346.

Natee, S., Low, S. P. and Teo, E. A. L. (2016). Decision Making and Quality Function Deployment (QFD). Quality Function Deployment for Buildable and Sustainable Construction, 17-55. doi:10.1007/978-981-287-849-6_2

Nonthaleerak, P. and Hendry, L. C. (2006). Six Sigma: literature review and key future research areas. International Journal of Six Sigma and Competitive Advantage, 2(2), 105. doi:10.1504/ijssca.2006.010111

Ohio University, The 7 Roles of Six Sigma, December 3, 2019, https://onlinemasters.ohio.edu/blog/the-7-roles-of-six-sigma/, Access Date: 12.03.2021)

Ocampo, L. A., Labrador, J. J. T., Jumao-as, A. M. B. and Rama, A. M. O. (2020). Integrated multiphase sustainable product design with a hybrid quality function deployment - multi-attribute decision-making (QFD-MADM) framework. Sustainable Production and Consumption. doi:10.1016/j.spc.2020.06.013

Quality Function Deployment (QFD), https://quality-one.com/qfd/ Access Date:10.08.2021

Relationship Between Quality and Sustainability, https://mcdcg.com/blog/quality/relationship-quality-sustainability/, Access Date: 13.05.2021.

Russ, R., DanaSperling, D., Rometsch R and PeterLouis P. (2008), Applying Six Sigma in the Field of Software Engineering, Lecture Notes in Computer Science, Springer , 5338, IWSM 2008: Software Process and Product Measurement, 36-47.

Six Sigma - A complete Step-by-Step Guide by The Council for Six Sigma Certifications (2018), CSSC publishing, 829 p.

Smith, G. (1993). Benchmarking success at Motorola, Copyright Soceity of Management Accountants of Canada, March.

Trappey, C. V., Trappey, A. J. C. and Hwang, S.-J. (1996). A computerized quality function deployment approach for retail services. Computers \& Industrial Engineering, 30(4), 611-622. doi:10.1016/0360-8352(95)00179-4.

Ur Rehman, H., Asif, M., Aamir Saeed, M., Asim Akbar, M. and Usman Awan, M. (2012). Application of Six Sigma at cell site construction: a case study. Asian Journal on Quality, 13(3), 212-233. doi:10.1108/15982681211287775

Van Iwaarden, J., Van Der Wiele, T., Dale, B., Williams, R. and Bertsch, B. (2008). The six sigma improvement approach: a transnational comparison. International Journal of Production Research, 46 (23), 6739-6758.

What is DMADV, Define-Measure-Analyze-Improve-Control (DMAIC), https://www.sixsigmadaily.com/what-is-dmadv/ Access Date: 16.03 .2021

What is quality? www.quality.org/what-quality, Access Date: 10.05.2021

What Is Quality Function Deployment (Qfd)?, https://asq.org/quality-resources/qfd-quality-function-deployment Access Date:10.08.2021.

What is Quality Management and Why Does it Matter? https://www.qualitymag.com/articles/95237-what-is-quality-management-and-whydoes-it-matter, Access Date: 10.05.2021

Why Quality Is Important for Sustainability, https://www.thewellessentials.com/blog/why-quality-is-important-for-sustainability, Access Date: 13.05.2021 
Yahya, S. and Kingsman, B. (1999). Vendor Rating for an Entrepreneur Development Programme: A Case Study Using the Analytic Hierarchy Process Method. The Journal of the Operational Research Society, 50(9), 916-930. doi:10.2307/3010189.

Yılmaz, H. (2009). Optimization of the product design through Quality Function Deployment (QFD) and Analaytical Hierarchy Process (AHP): A case study in a ceramic washbasin, Yüksek Lisans Tezi, İzmir Yüksek Teknoloji Enstitüsü, Mühendislik ve Fen Bilimleri Enstitüsü, 91-92.

$\mathrm{Zu}, \mathrm{X}$., Fredendall, L.D. and Douglas, T.J. (2008). The evolving theory of quality management: the role of Six Sigma. Journal of Operations Management, 26(5), 630-50. 